\title{
Estimating feature extraction changes of Berkelah Forest, Malaysia from multisensor remote sensing data using an object-based technique
}

Syaza Rozali ${ }^{1}$, Zulkiflee Abd Latif ${ }^{1}$, Nor Aizam Adnan ${ }^{1}$, Yousif Hussin ${ }^{2}$, Alan Blackburn ${ }^{3}$, Biswajeet Pradhan ${ }^{4,5,6,7}$

${ }^{1}$ Applied Remote Sensing \& Geospatial Research Group (ARSG), Centre of Studies for Surveying Science and Geomatics, Faculty of Architecture, Planning and Surveying, Universiti Teknologi MARA (UiTM), 40450 Shah Alam, Selangor, Malaysia.

${ }^{2}$ Department of Natural Resources, Faculty of Geo-information Science and Earth Observation (ITC), University of Twente, 7500 AE Enschede, The Netherlands.

${ }^{3}$ Lancaster Environment Centre, LEC Building, Lancaster University, LA1 4YQ U.K.

${ }^{4}$ The Centre for Advanced Modelling and Geospatial Information Systems (CAMGIS), School of Information, Systems \& Modelling, Faculty of Engineering and Information Technology, University of Technology Sydney, NSW 2007, Australia

${ }^{5}$ Center of Excellence for Climate Change Research, King Abdulaziz University, P. O. Box 80234, Jeddah 21589, Saudi Arabia

${ }^{6}$ Department of Energy and Mineral Resources Engineering, Sejong University, Choongmu-gwan, 209 Neungdong-ro, Gwangjin-gu, Seoul 05006, Korea

${ }^{7}$ Earth Observation Center, Institute of Climate Change, Universiti Kebangsaan Malaysia, 43600 UKM, Bangi, Selangor, Malaysia 